\title{
Performance evaluation of accelerometers ADXL345 and MPU6050 exposed to random
}

\section{vibrational input}

\author{
Avaliação do desempenho dos acelerômetros ADXL345 e MPU6050 expostos a vibrações randômicas \\ Evaluación del desempeño de los acelerómetros ADXL345 y MPU6050 expuestos a vibraciones
}

aleatorias

\author{
João Victor Oliveira Rodrigues \\ ORCID: https://orcid.org/0000-0003-4249-5921 \\ Federal Institute of Minas Gerais, Brazil \\ E-mail: joaovr73@gmail.com \\ Marcos Paulo Gonçalves Pedroso \\ ORCID: https://orcid.org/0000-0001-7088-2916 \\ Federal Institute of Minas Gerais, Brazil \\ E-mail: marcos.pedroso@ifmg.edu.br \\ Flávio Fernandes Barbosa Silva \\ ORCID: https://orcid.org/0000-0003-4823-2014 \\ Federal Institute of Minas Gerais, Brazil \\ E-mail: flavio.fernandes@ifmg.edu.br \\ Reginaldo Gonçalves Leão Junior \\ ORCID: https://orcid.org/0000-0002-3596-2256 \\ Federal Institute of Minas Gerais, Brazil \\ E-mail: reginaldo.junior@ifmg.edu.br
}

\begin{abstract}
The use of vibration monitors is a well-established practice in industrial maintenance, usually vibration sensors are positioned at specific points on the monitored machinery and data are continuously collected to feed a machine operating health control system. Nevertheless, the technology for obtaining the signal, its treatment and analysis is generally expensive, and the financial return is not evident, which justifies the development of low-cost alternatives technologies. In this work was performed an analysis of the responses of two Micro-Electro-Mechanical accelerometers, models ADXL345 and MPU6050, exposed to a low intensity random signal and standard operating frequency. The objective of the analysis was to verify the capacity of these devices to be used as mechanical vibration sensors for rotating machines. For this purpose, offset shift analyzes of the sensors due to the Earth's gravitational field were performed, as well as vibrational spectrum and rectification errors analysis under multiple conditions. The data pointed to a greater uniformity of the MPU6050 response, while several behavioral anomalies were seen in the ADXL345, when these sensors are exposed to the same mechanical signal. The qualitative and quantitative behavior of MPU6050 rectification error was consistent with reported in the literature. It was noted that the methodology used can profile the behavior of sensors, however, it is not sufficient to safely justify the inaccuracies, requiring that the tests be performed on a statistically representative number of sensors from different manufacturers and batches.
\end{abstract}

Keywords: MEMS; Accelerometers; Mechanical vibrations; Offset shifts; Rectification errors.

\section{Resumo}

O uso de monitores de vibração é uma prática bem estabelecida na manutenção industrial, geralmente sensores de vibração são posicionados em pontos específicos do maquinário monitorado e dados são continuamente coletados para alimentar um sistema de controle de integridade operacional. No entanto, a tecnologia de obtenção do sinal, tratamento e análise geralmente é cara e o retorno financeiro não evidente, o que justifica o desenvolvimento de tecnologias alternativas de baixo custo. Neste trabalho foi realizada uma análise das respostas de dois acelerômetros microeletromecânicos, modelos ADXL345 e MPU6050, expostos a um sinal aleatório de baixa intensidade e frequência de operação padrão. O objetivo da análise foi verificar a capacidade desses dispositivos em serem utilizados como sensores mecânicos de vibração em máquinas rotativas. Para tanto, foram realizadas análises de offset shift dos sensores devido ao campo gravitacional terrestre, bem como análises de espectro vibracional e erros de retificação. Os dados apontaram para uma maior uniformidade da resposta do MPU6050, enquanto várias anomalias comportamentais foram observadas no ADXL345, quando esses sensores são expostos ao mesmo sinal mecânico. O comportamento qualitativo e quantitativo do erro de retificação MPU6050 foi consistente com o relatado na literatura. Observou-se ainda que a metodologia utilizada pode traçar o perfil do comportamento dos sensores, porém, não é suficiente para justificar com segurança as imprecisões, 
exigindo que os testes sejam realizados em um número estatisticamente representativo de sensores de diferentes fabricantes e lotes.

Palavras-chave: MEMS; Acelerômetros; Vibrações mecânicas; Offset shifts; Erros de retificação.

\section{Resumen}

El uso de monitores de vibración es una práctica bien establecida en el mantenimiento industrial, generalmente los sensores de vibración se colocan en puntos específicos de la maquinaria monitoreada y los datos se recopilan continuamente para alimentar un sistema de control de integridad operacional. Sin embargo, la tecnología para obtener la señal, procesarla y analizarla es generalmente costosa y la rentabilidad económica no es evidente, lo que justifica el desarrollo de tecnologías alternativas de bajo costo. En este trabajo se realizó un análisis de las respuestas de dos acelerómetros microelectromecánicos, modelos ADXL345 y MPU6050, expuestos a una señal aleatoria de baja intensidad y frecuencia de operación estándar. El objetivo del análisis fue verificar la capacidad de estos dispositivos para ser utilizados como sensores mecánicos de vibración en máquinas rotativas. Para ello, se realizaron análisis de offset shift de los sensores debido al campo gravitacional terrestre, así como análisis de espectro vibratorio y errores de rectificación. Los datos apuntaban a una mayor uniformidad de la respuesta del MPU6050, mientras que se observaron varias anomalías de comportamiento en el ADXL345, cuando estos sensores están expuestos a la misma señal mecánica. El comportamiento cualitativo y cuantitativo del error de rectificación del MPU6050 fue consistente con lo reportado en la literatura. También se observó que la metodología utilizada puede perfilar el comportamiento de los sensores, sin embargo, no es suficiente para justificar con seguridad las inexactitudes, requiriendo que las pruebas se realicen en un número estadísticamente representativo de sensores de diferentes fabricantes y lotes.

Palabras clave: MEMS; Acelerómetros; Vibraciones mecânicas; Offset shifts; Errores de rectificación.

\section{Introduction}

The most common deleterious vibrations in rotating machines are mainly associated with unbalanced rotations and the eccentricity of rotary shafts. Because of this, the phenomenon must be carefully and frequently monitored by means of the appropriate instrumentation and precise techniques.

An in-depth understanding of the dynamic response resulting from unbalances and eccentricities is essential for evaluating data from the monitoring of rotating machines and assessing the severity of the process and potential damage (Correa \& Guzman, 2020). This phenomenon can be modeled in a simplified way if the system is described as shown in Figure 1.

Figure 1. Simplified representation of a vibrating system with an unbalanced $m_{0}$ mass element.

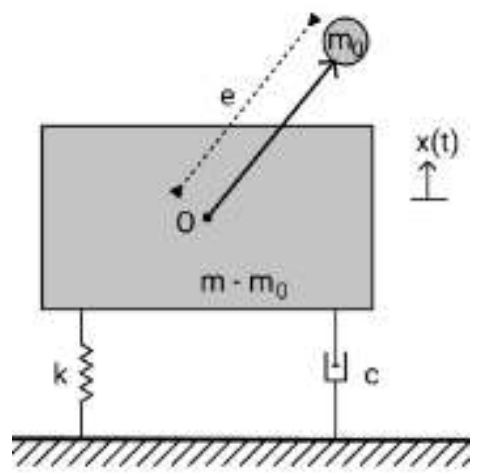

Source: Authors.

This idealized model can be described as a body of mass $m$, of which a fraction of mass $m_{0}$ rotates around the pole $O$, however, without having another equivalent fractional mass in a symmetrical position. The presence of a mass element in this condition means that the system can be analyzed using two different free-body diagrams. In the first, only the mass fraction $m_{0}$ is considered and in the second the rest mass of the system. In rotating part, acts only the force $F^{\prime}{ }_{0}$ applied by its link with the rest of the system in the origin, simultaneously the reaction $F_{0}$ acts in the body with mass $m-m_{0}$. Applying Newton's second law to the system, it is possible to determine that the general equation for this motion can be determined in the form of Eq 1 
(Dukkipati \& Srinivas, 2010).

$$
m \ddot{x}+c \dot{x}+k x=-e m_{0} \omega_{r}^{2} \sin \left(\omega_{r} t\right)
$$

Where $e$ is the radius of $m_{0}, \omega_{r}$ is the angular velocity and the damping constant $c$. Considering the fundamental definitions of viscous damping factor $(\zeta)$ and natural frequency $(\omega n)$ as the expressed in Eqs. 2 and 3, Eq. 1 can be simplified to the form of Eq. 4.

$$
\begin{gathered}
\omega_{n}^{2}=\frac{k}{m} \\
\zeta=\frac{c}{2 m \omega_{n}} \\
\ddot{x}+2 \zeta \omega_{n} \dot{x}+\omega_{n}^{2} x=\frac{m_{0}}{m} e \omega_{r}^{2} \sin \left(\omega_{r} t\right)
\end{gathered}
$$

Knowledge of the model expressed by Equation 4 is essential for the spectral analysis of signals detected in rotating machines, since the adequacy or inadequacy of the signal to the model allows checking the presence of deleterious harmonics (Blodt et al, 2006; Wang, He, \& Zi, 2010).

Large rotating machines such as centrifugal compressors, gas/steam turbines and electricity generators, generally have high mass rotors, however, they obviously have limitations on rigidity of their respective shafts. In addition, these machines generally operate at rotational speeds higher than its critical speed $\left(\omega_{n}\right)$, in a mode of operation commonly called supercriticality. It is peculiar working conditions makes the start-up and shut-down periods especially worrying, as in these phases the vibration indices reach critical conditions. Energy dissipation generally occurs by means of an effective damping system especially required under these conditions (Friswell et al, 2010; Less, Sinha, \& Friswell, 2009; Combescure \& Lazarus, 2008).

Despite the protection mechanisms, these particularities are associated with vibration-generating mechanisms which must be well understood. The possibility of unbalance - due to unequal mass distributions, already as mentioned - and inertial effects, may provoke temporary deformations in the shafts, causing deflections that induce quite severe vibrations generally not consistent with the standard levels (Farrar, Doebling, \& Nix, 2001; Yan et al, 2007). In Figure 2, the cross section of a shaft in which its center of mass $C_{m}$ is displaced from the geometric center $C_{s}$ by a value of $\varepsilon$.

Figure 2. Vector representation of a w-induced deformation in the cross section of the shaft of a rotating machine.

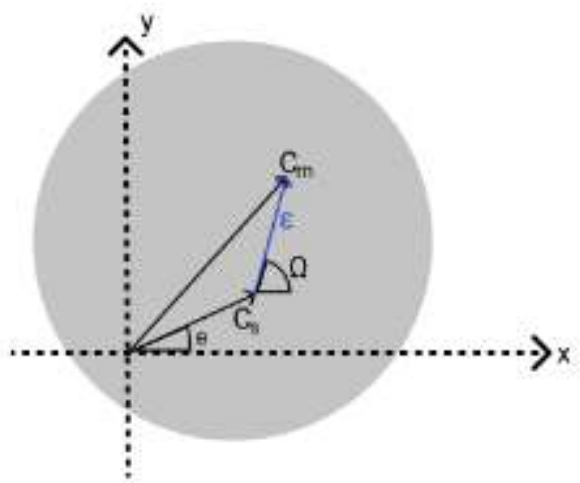

Source: Authors 
If the deformation experienced by the shaft is elastic, then the balance of forces conditions suggest that these may be modeled by Eqs. 5 and 6 which, after the differential operations are indicated as in Eqs. 7 and 8 (Kelly, 2012; Dukkipati \& Srinivas, 2010).

$$
\begin{array}{r}
m \frac{d^{2}}{d t^{2}}\left(x+\varepsilon \cos (\Omega)+k_{x} x\right)=0 \\
m \frac{d^{2}}{d t^{2}}\left(y+\varepsilon \cos (\Omega)+k_{y} y\right)=0 \\
\left.\mathrm{~m}\left(\ddot{x}+\varepsilon \dot{\Omega^{2}} \cos (\Omega\}\right)-\varepsilon \ddot{\Omega} \sin (\Omega)+\mathrm{k}_{\mathrm{x}} \mathrm{x}\right)=0 \\
\left.\mathrm{~m}\left(\ddot{y}+\varepsilon \dot{\Omega^{2}} \sin (\Omega\}\right)-\varepsilon \ddot{\Omega} \cos (\Omega)+\mathrm{k}_{\mathrm{y}} \mathrm{y}\right)=0
\end{array}
$$

In synchronous systems, it must be admitted that $\dot{\Omega}=\dot{\omega}$ and $\ddot{\Omega}=\ddot{\omega}$ making it possible to simplify the Eqs. 7 and 8 for the forms of Eqs. 9 and 108 (Kelly, 2012; Dukkipati \& Srinivas, 2010).

$$
\begin{aligned}
& \ddot{x}+\omega_{n x}^{2} x=\varepsilon \omega^{2} \cos (\omega t) \\
& \ddot{y}+\omega_{n y}^{2} y=\varepsilon \omega^{2} \sin (\omega t)
\end{aligned}
$$

As discussed for Eq. 4, knowledge of the models represented by Eqs. 9 and 10 is fundamental to identify the sources of mechanical vibrations in the appropriate cases.

The ISO 20816-1 (2016) standard determines that vibrations in rotating machine systems are determined by the effective value (rms) of the vibration speed of the studied system. The ISO standard differentiates 15 degrees of severity in an interval between $0.11-71.00 \mathrm{~mm} . \mathrm{s}^{-1}$ that can be qualified by associating the frequency (Hz) and rms values (mm.s $\left.{ }^{-1}\right)$. In this qualification, the satisfaction restrictions for the standardized frequencies should not be much greater than $5 \mathrm{rms}$.

For structural risks, the ISO 4866 (2010) standard also predicts some probability of minor damage to structural elements for values greater than $5 \mathrm{rms}$ in a frequency range with higher level in $100(\mathrm{~Hz})$ and displacements that do not exceed $10 \mu \mathrm{m}$. Higher values are associated with severe structural damage.

\subsection{Mechanical Vibration Sensing with Accelerometers}

Accelerometers are circuits specially prototyped to promote the conversion of mechanical vibrations in electrical signals, due to these unique properties, they are classified as electromechanical transducers. Its use in vibration monitoring systems is already well established, however, accelerometers used as monitoring instruments widely available on the market are essentially piezoelectric or type ICP (Integrated Circuit Piezoelectric), whose costs are high (Bao, 2000; Levinzon, 2015).

From the 80's, with the viability of Microelectromechanical Systems (MEMs), and its industrial-scale production started in the 2000s, many micro-electro-mechanical components were developed, and among the first were exactly the accelerometers (Albarbar \& Teay, 2017; Walter, 1997).

A MEMS device is a microcircuit that combines mechanical properties with electrical properties generating an interface between phenomena mechanics and electronics on a microscopic scale. Accelerometers developed using this technology are composed of three main elements; i) a seismic mass, ii) a system of micro-springs that anchor the mass to the circuit substrate; 
and iii) and a system of multiples parallel plate capacitors as shown in Figure 3 (He et al, 2018). When the seismic mass is subjected to some acceleration, the springs allow the side plates of this mass to permeate a dielectric region fraction of the capacitors. The presence of this material inside the electric field, causes a variation in the capacitance of the system, generating an electrical disturbance, that can be captured by metering the electrical current between the plates in an intermediate circuit (Bao, 2005; Tanaka, 2007).

Figure 3. Generalization of a micromachine of a MEMS accelerometer.

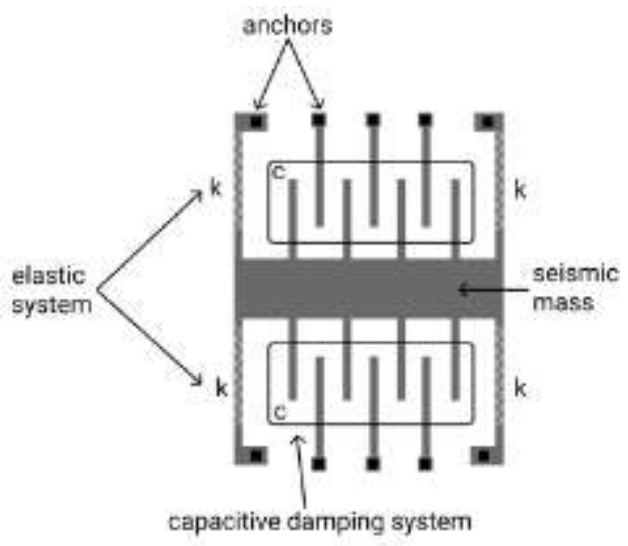

Source: Authors.

The intensity of this current, the changes in electrical potential at the terminals of each capacitor, together with information about the elastic constant of the spring, allows an acceleration prediction of the seismic mass. The signal generated by this micromachine can be amplified and used as an analog output or can be routed to a analog to digital converter and processed by some integrated circuit before being routed to the output of the board. The potential difference generated by electromechanical events in the device can be modeled by Eq. 11 (Silva, 2014; Tanaka, 2007).

$$
V_{\text {out }}=\frac{C V_{m} a}{2 C+C_{p}+k}
$$

Where $C$ is the capacitance of the undisturbed system, $C_{p}$ is the parasitic capacitance manifested between the plates of the capacitors and the plates of the seismic mass, $k$ is a constant that accounts the disturbance in capacitance due to presence of electronic components associated with MEMS, $\omega_{n}$ is the natural frequency of the system 'seismic mass $x$ spring' and the acceleration of the mass.

The ability of an accelerometer to provide reliable responses upon mechanical excitation is determined by five distinct criteria:

i) the sensitivity, which relates the intensity of the electrical signal in $(V)$ with the amplitude of vibration;

ii) the range of frequencies supported by the circuit;

iii) the maximum supported vibration amplitude;

iv) the limit of shock, which determines the maximum acceleration supported by the MEMS;

v) the linearity, which indicates the adherence of the responses from the accelerometer to a given mathematical model in the supported frequency range.

The analysis of these characteristics, associated with implementation costs, are ideal guiding devices for the selection of the ideal accelerometer for a given application (Lawes, 2014). 
The main objective of this work was to evaluate the performance of two low-cost MEM type accelerometers exposed to a random and low intensity mechanical signal. Analyzes were performed in the time and frequency domain under variable conditions, in addition to the seismic disturbances felt by the devices in different orientations in relation to the gravitational field. Due to experimental restrictions, this first analysis was carried out with a focus on the use of devices for operational monitoring of low power and inertia rotating machines, considering operational demand situations and slightly above the nominal ones.

\section{Methodology}

Two experiments were used to characterize the accelerometers, the measure of the Offset Shifts due to the gravitational field and the measure of vibrational profile of the inputs caused by a motor of direct current with rotating speed controlled by a variable power supply voltage. The following main items were used to assemble the setups:

i) Digital inclinometer with $0.05^{\circ}$ resolution;

ii) Arduino UNO R3 board;

iii) Accelerometers (MPU6050 and ADXL345);

iv) Adjustable level metal base;

v) Acrylic support frame.

The initial measurement setups can be seen in Figure 4.

Figure 4. Setup for data collection for offset shifting. a) Calibration and operational test of the Arduino board. b) Sensor positioned on the acrylic support for measurements in multiple orientations.
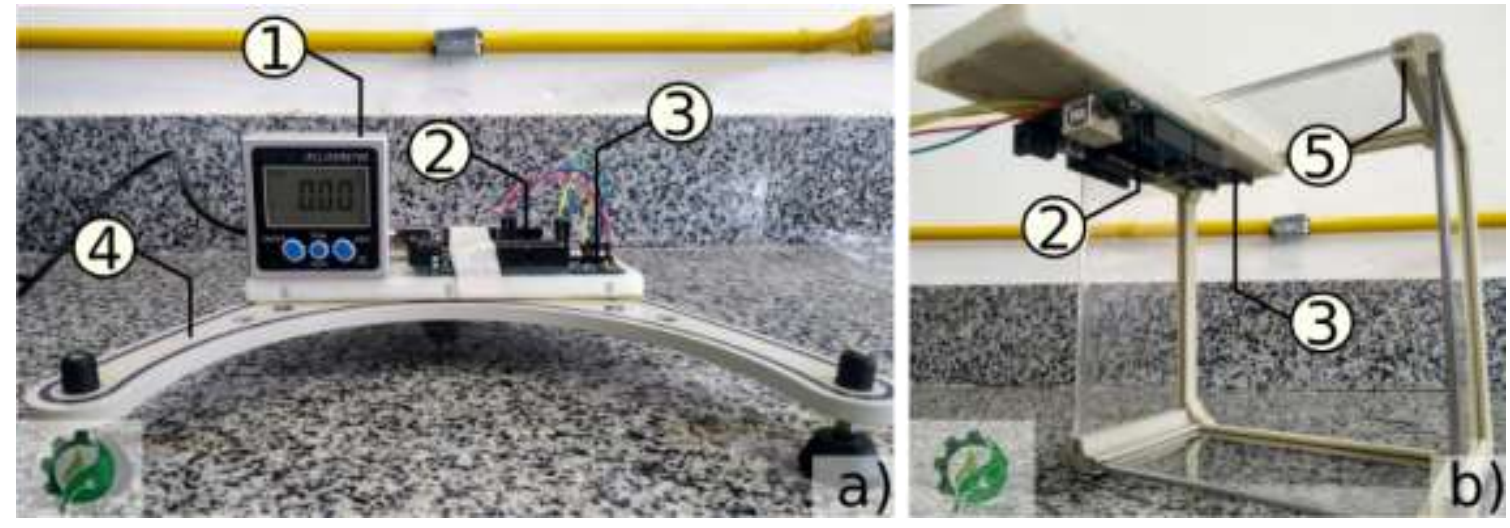

Source: Authors.

\subsection{Obtaining Offset Shifts}

The first experiment consisted of measuring the accelerations perceived by the seismic mass due to the Earth's gravitational field.

For each axis of operation of the accelerometers ( $\mathrm{x}, \mathrm{y}$ and $\mathrm{z}$ ) two measurements are taken. The first one with the operating axis oriented in the direction of the gravitational field and the second one in the opposite direction. Figure $1 \mathrm{~b}$ ) shows the reading system attached to the acrylic support to allow multiple orientations, and Figure 5, shows a representation of the measurement procedure for the z-axis. 
Figure 5. Accelerometer positioning scheme for measuring offset shifts.

measure 1

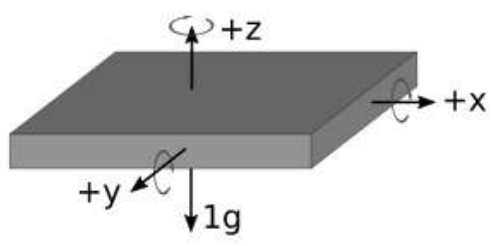

measure 2

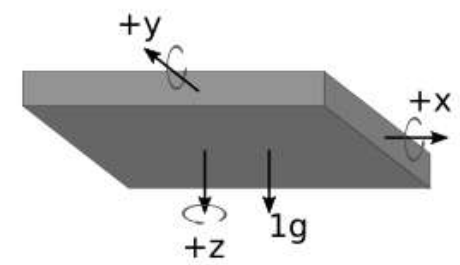

Source: Authors.

From the data, the offset shift values could be calculated according to Eq. 12 (Fisher, 2010).

$$
A_{o f f(x, y, z)}=0.5\left(A_{+g_{(x, y, z)}}+A_{-g_{(x, y, z)}}\right)
$$

Data collection was performed automatically by the Arduino board, starting data compilation after $5 \mathrm{~s}$ after the beginning of the exposure and ending after approximately $12 \mathrm{~s}$ of data collection.

\subsection{Obtaining the vibration data}

Vibration data were obtained in $a . g$ mode (multiples of $\mathrm{g}$ ) and amplitudes, allowing a more transversal assessment of the system. Data obtained in $a . g$ mode were used for spectral analysis in time and frequency, while the amplitude data are not presented in this work due to the extension of the analysis performed for the accelerations.

The vibrational data were obtained only in the $+z /-g$ orientation ( $\mathrm{z}$ axis opposite to the gravity vector orientation), for 12 seconds and with motor operating voltages varying unitarily between $5 \mathrm{~V}$ and $13 \mathrm{~V}$. These data were then processed numerically to obtain spectrograms and g-Amplitude versus Voltage adjustments.

The entire process of automating readings and creation of graphics was developed by the authors themselves through the development of a Python library specialized in this type of analysis. The curve fitting and spectral decomposition used algebraic and numerical tools from the NumPy, SciPy and Matplotlib libraries (Harris et al, 2020; Virtanen et al, 2020; Hunter, 2007). The more specialized numerical treatment methods were developed with the support of the Group of Studies on Energy Systems and Computational Simulation (GESESC) at the Federal Institute of Minas Gerais (IFMG).

\subsection{Vibration Rectification Error estimative}

The estimate of Vibration Rectification Error (VRE) was performed using the methodology proposed by Phem and DeSimone (2017), the probability density function $\Phi(\xi)$ set to between sensor reading limits $\pm R$ is given by the equation Eq. 13.

$$
\Phi(\xi)=\frac{1}{\sqrt{2}} \exp \left(\frac{-1}{2} \xi^{2}\right)
$$

While the cumulative distribution function is given by Eq. 14 .

$$
\Phi(\xi)=\frac{1}{2}\left[1+\operatorname{erf}\left(\frac{\xi}{\sqrt{2}}\right)\right]
$$

For both, (Eqs. 13 and 14) $\xi$ assumes the values given by Eq. 15 . 


$$
\xi_{1,2}=\frac{ \pm R-\mu}{\sigma}
$$

Where $\mu$ is the mean of the normal distribution of the sensor input excitations, corrected by the Offset Shifts and $\sigma$ the rms input vibration in amplitude. The sensor output is then determined by Eq. 16 and the VRE determined by the difference between the output and $\mu$, as shown in Eq. 17 .

$$
\begin{gathered}
\mu^{\prime}=\mu+\frac{\Phi\left(\xi_{1}\right)-\Phi\left(\xi_{2}\right)}{\Phi\left(\xi_{2}\right)-\Phi\left(\xi_{2}\right)} \sigma \\
V R E=\mu^{\prime}-\mu
\end{gathered}
$$

\section{Results and Discussions}

\subsection{Offset shifts}

The offset shifts measured on each accelerometer are shown in the Figure 6. The mean offset shifts and peaks are transcribed in Table 1

Table 1. Average and peak of offset shifts.

\begin{tabular}{|c|c|c|c|c|}
\hline & Average & Peake & Average & Peake \\
\hline$x$ & $\gtrsim 0.0175$ & $\cong 0.030 \uparrow$ & $\lesssim 0.098$ & $\cong 0.086 \downarrow$ \\
\hline$y$ & $\gtrsim 0.0175$ & $\cong 0.030 \uparrow$ & $\lesssim 0.084$ & $\cong 0.076 \downarrow$ \\
\hline$z$ & $\gtrsim 0.020$ & $\cong 0.03 \uparrow$ & $\gtrsim 0.096$ & $\cong 0.104 \uparrow$ \\
\hline
\end{tabular}

MPU 6050

ADXL 345 
Figure 6. Offset shifts organized by accelerometer type and operation axis.

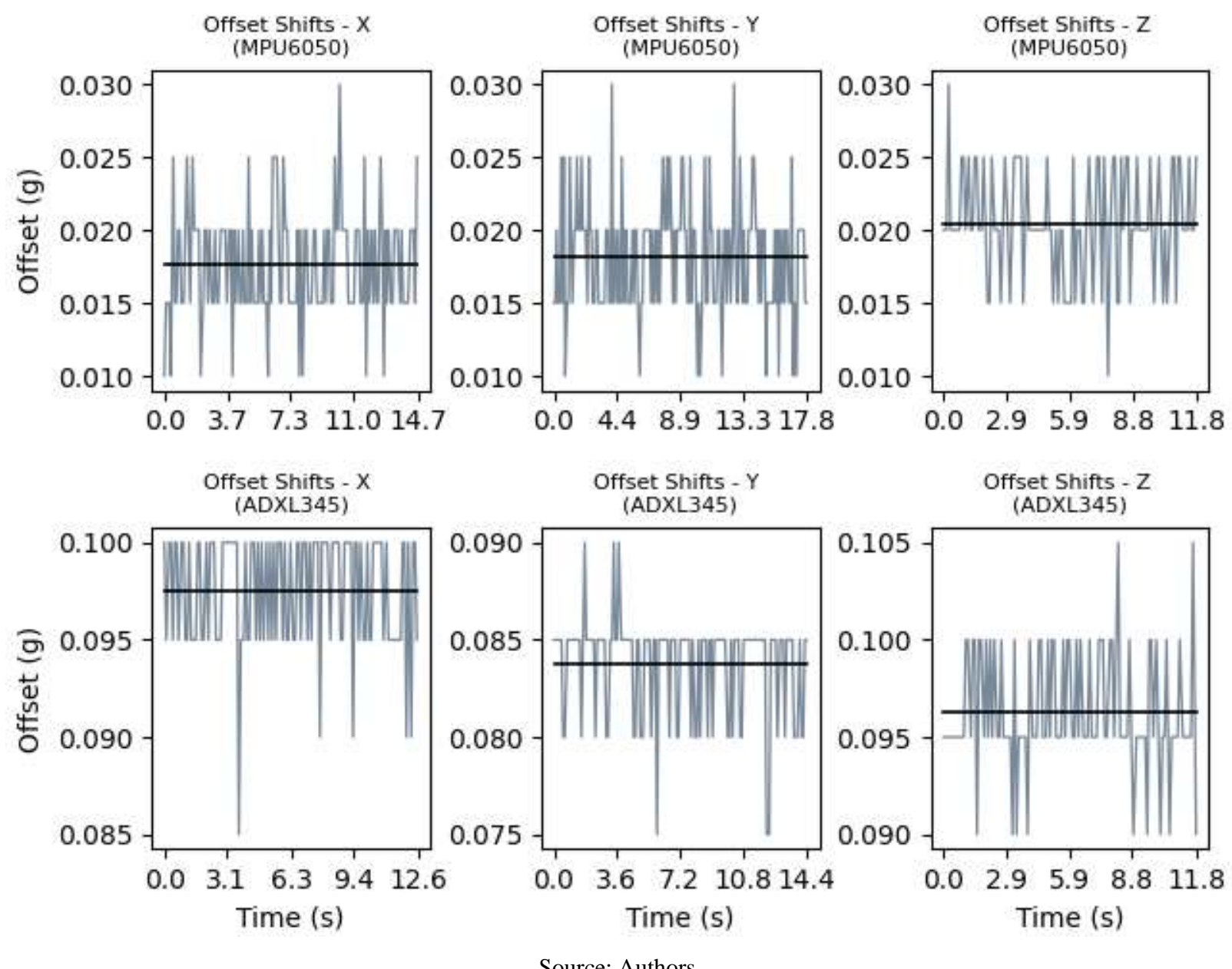

Source: Authors.

The data show a greater behavioral uniformity of the MPU6050 when compared to the ADXL345, as well as smaller reading deviations in all axes of operation. The occurrence of discrepant values from the average behavior may be indicative of the induction of reading errors due to random shocks during the experiment. On the $6050 \mathrm{MPU}$ these values are much more common than on the ADXL345, indicating a greater stability of this second to compensate effects of random errors due to low intensity shocks. However, this greater stability indicates the possibility of underestimating low intensity spectral components. Making it more suitable for application in situations where values of this level are not an object of study. Overall, the ADXL345 offset shifts are on average 5 times greater than those noted on the MPU6050, indicating a greater directional stability of this accelerometer.

\subsection{Time and frequency domain analysis}

As expected, time domain data analysis does not reveal very significant information about the behavior of accelerometers under the same operating conditions. As can be seen in Figures 7 and 8, the differences between the readings corrected by the respective offset shift remained in the $10 \%$ range for all tested cases. The readings taken by the MPU6050 show a clear increase in the intensity of vibrations as the operating voltage of the motor is increased, but the same does not happen for the ADXL345, when it does simultaneous readings. The measured amplitudes show an abnormal increase between the operating voltages of the motor, which range from 6 to 11 Volts, and decrease when voltages of 12 and 13 Volts are used. 
Figure 7. Accelerations (g) measured by the MPU6050 in the time domain.

MPU6050 - g (time domain).
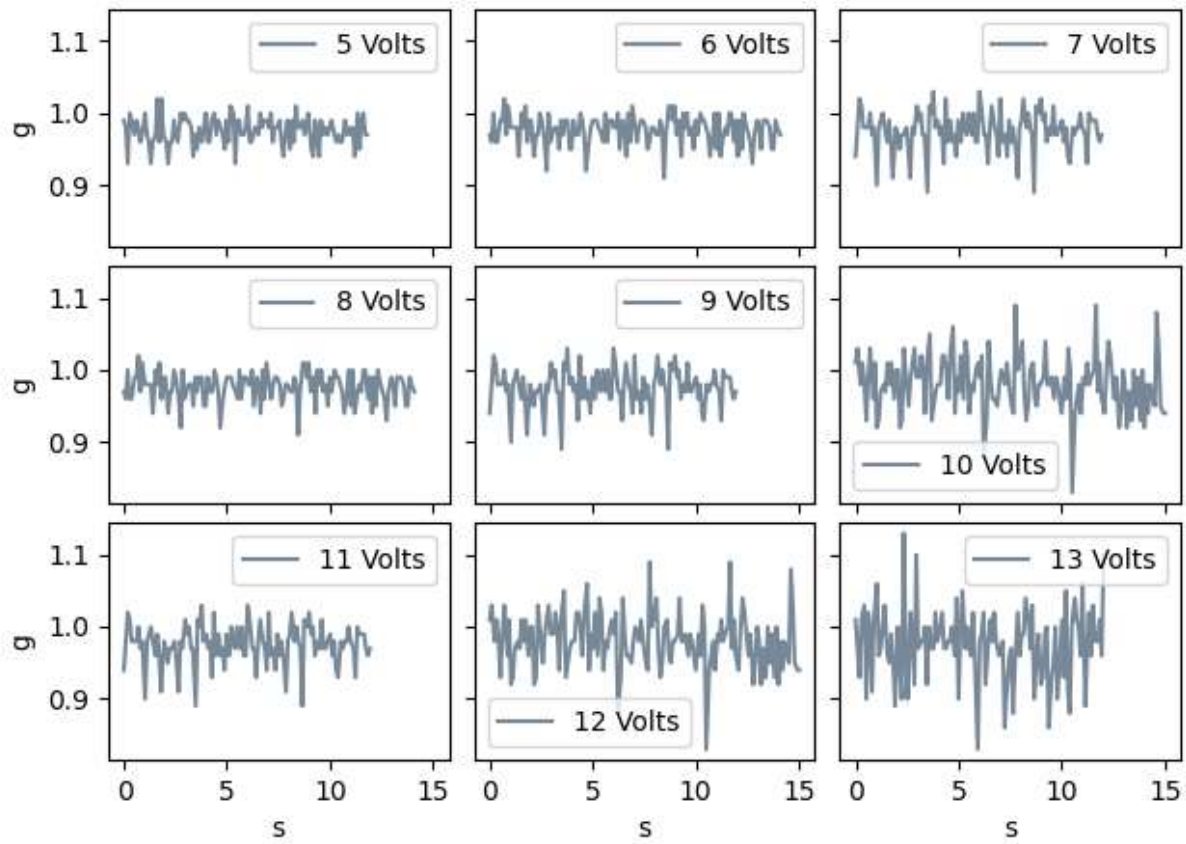

Source: Authors.

With the data obtained in this work it is not possible to safely explain the causes for this behavioral distinction, however an evaluation of this effect was carried out in order to assess its real magnitude.

Figure 8. Accelerations (g) measured by the ADXL345 in the time domain.

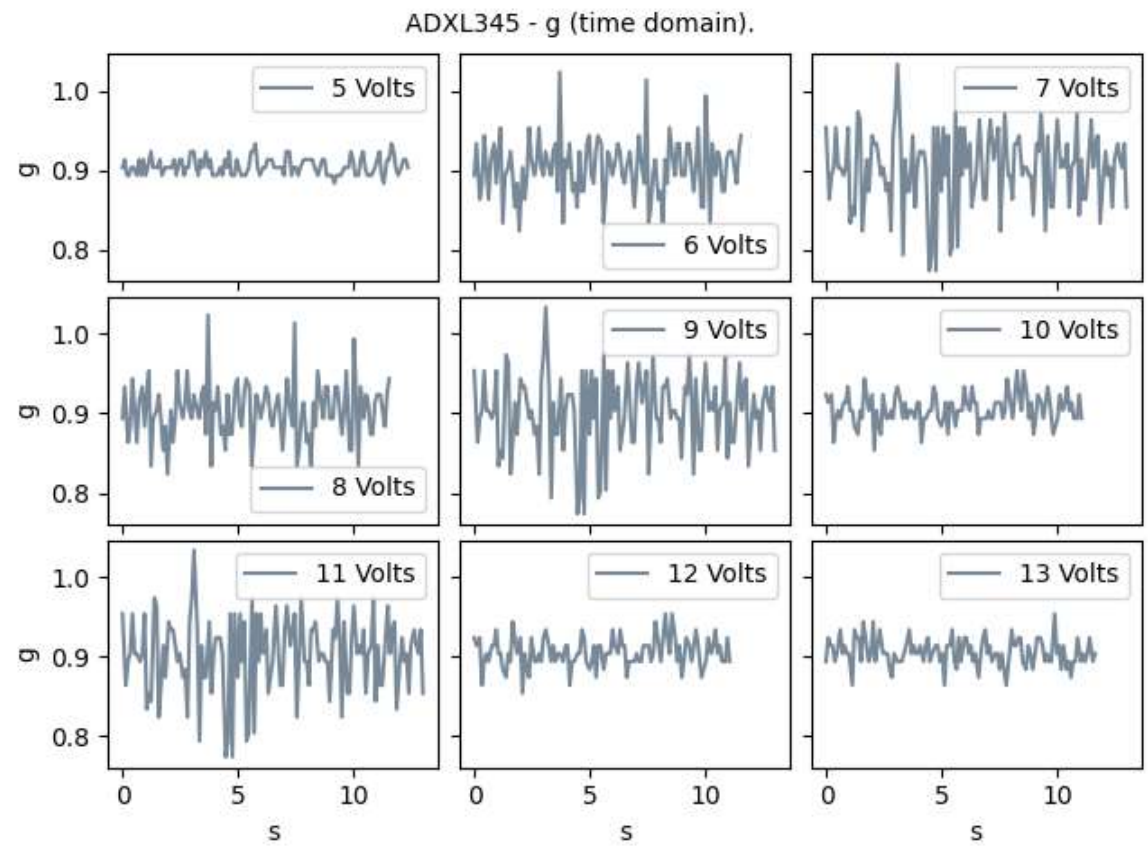

Source: Authors. 
Figures. 9 and 10 show the maximum and minimum g amplitudes measured for each operating voltage. In Figure 9 we can see the reasonable behavior of the MPU6050 showing increases in reading peaks when the voltage is increased.

Figure 9. Maximum and minimum signal amplitudes measured in $\mathrm{g}$ on the MPU6050.

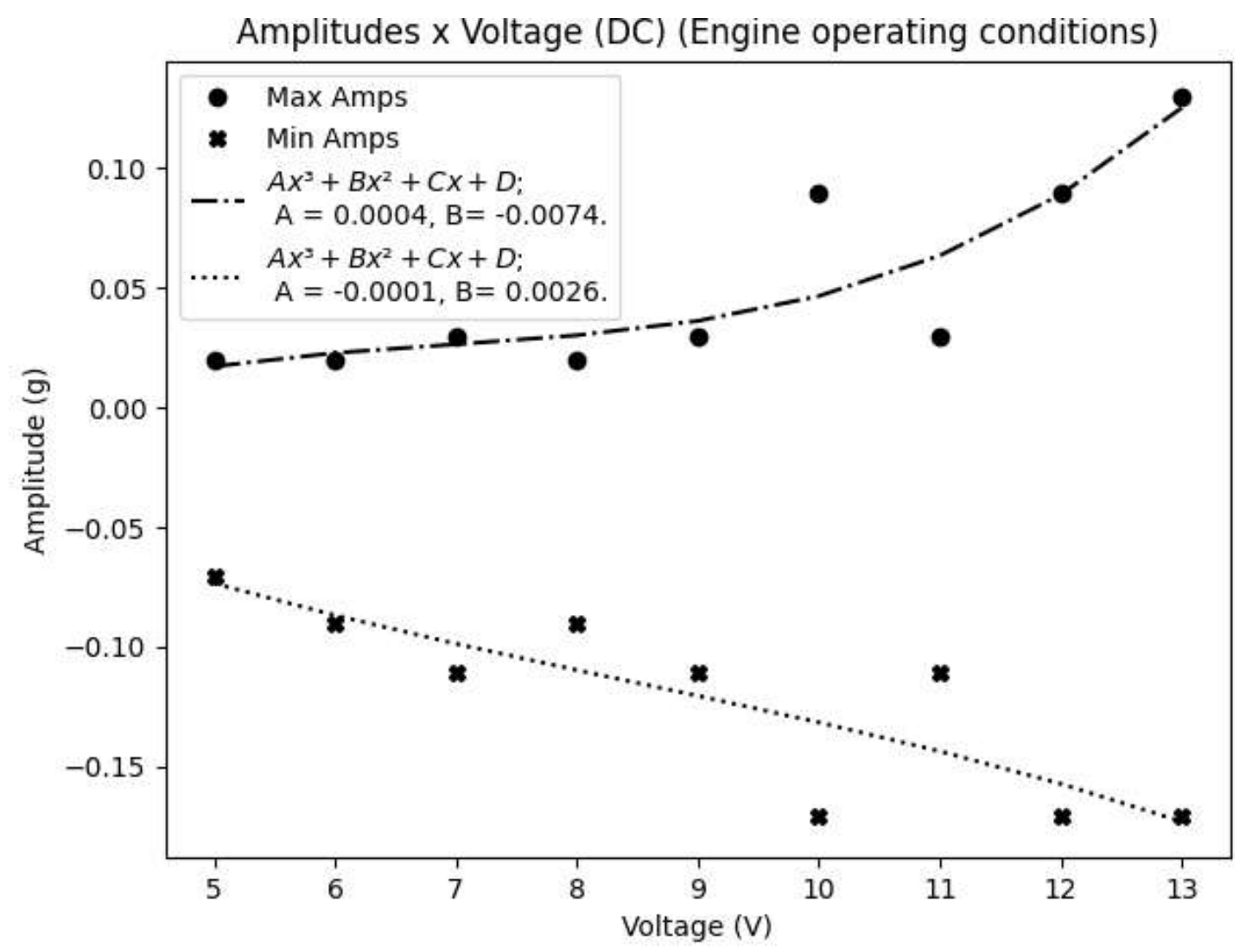

Source: Authors.

However, in Figure 10 the same is not observed. It is noteworthy that the peak vibrational intensity perceived by the ADXL345, occurs when the motor operates at 7V and has an absolute maximum amplitude greater than $0.15 \mathrm{~g}$. While the simultaneous reading of the MPU6050 indicates something slightly higher than $0.10 \mathrm{~g}$. From this point onwards, the ADXL345 presents some randomness in the $\mathrm{g}$ readings, but with an overall behavior converging to $0 \mathrm{~g}$, while the MPU6050 points to a continuous increase in accelerations.

The polynomial fit (least squares) shown in the graphs has the sole purpose of demonstrating the behavioral trends of the collected data and is not used as a reasonable behavioral model, although the adherence of the curves to the data has been shown to be satisfactory in 3 of 4 adjustments performed, indicating the possibility of composing curves of this nature for higher sample rates and more versatile mathematical models than a third-order polynomial. 
Figure 10. Maximum and minimum signal amplitudes measured in $g$ on the ADXL345.

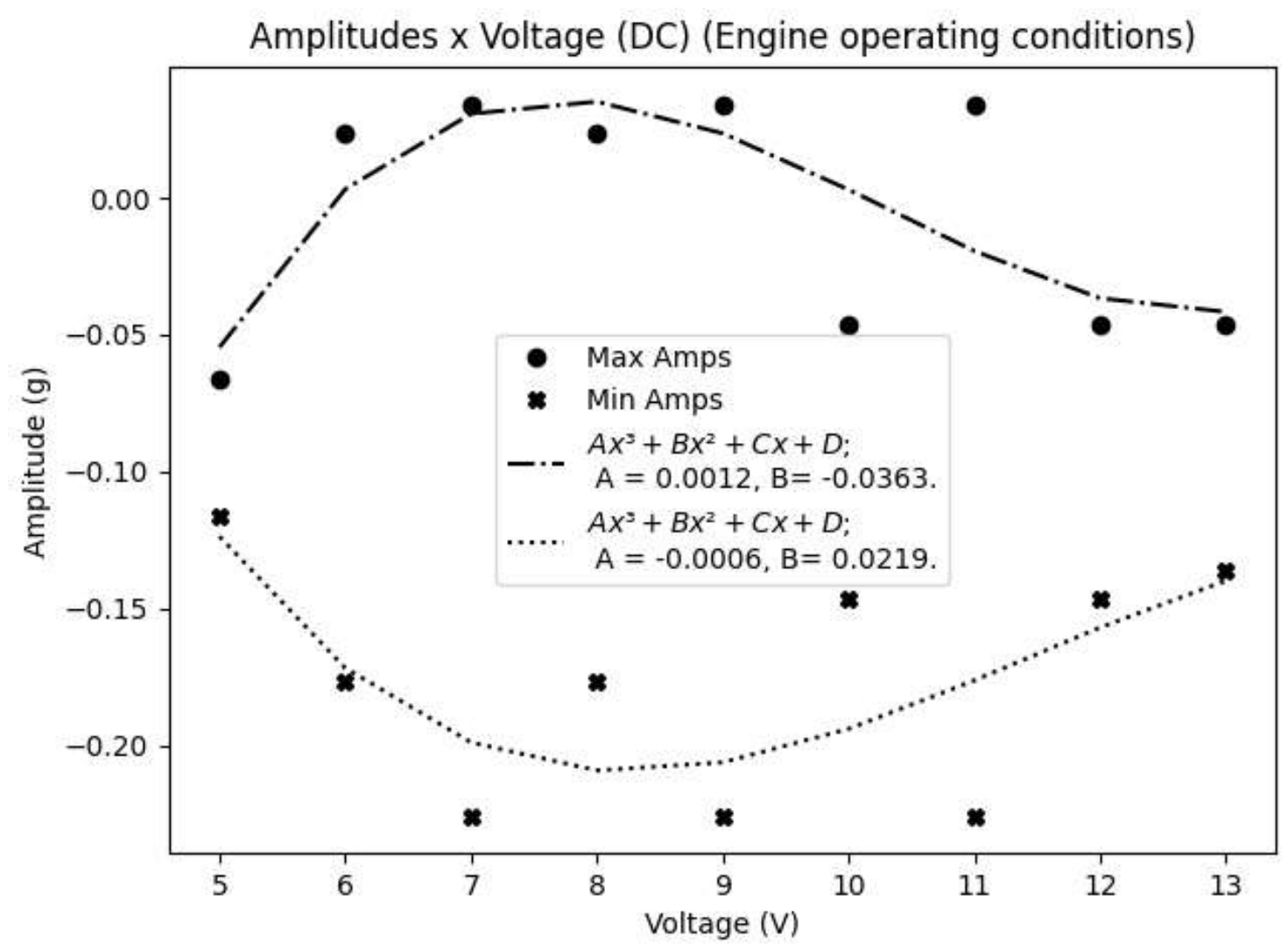

Source: Authors.

The spectral composition of the signal measured in accelerometers also showed a high degree of divergence in the level of experimental exposure. The nominal rotation frequency for $12 \mathrm{~V}$ is highlighted in Figure 11 . It is noteworthy that this component can be reasonably distinguished, across the entire operating range of the engine $(5-12 \mathrm{~V})$ when readings from the MPU6050 are analyzed.

On the other hand, this peak is not clearly identifiable in the data measured on the ADXL345. With the exception, perhaps, for 5 and $12 \mathrm{~V}$, as can be seen in Figure 12.

An assessment of the spectral similarities and divergences measured by the two sensors, however, requires its own methodology that is beyond the scope of this work. Probably modern signal processing techniques like Mel Frequency Cepstrum Coefficients can bring more clarity to the issue (Prawin \& Anbarasan, 2021). A simple analysis of the spectral differences, however, reveals a curious behavior, but the data obtained cannot explain it clearly. 
Figure 11. Spectral composition of the signal measured by the MPU6050.

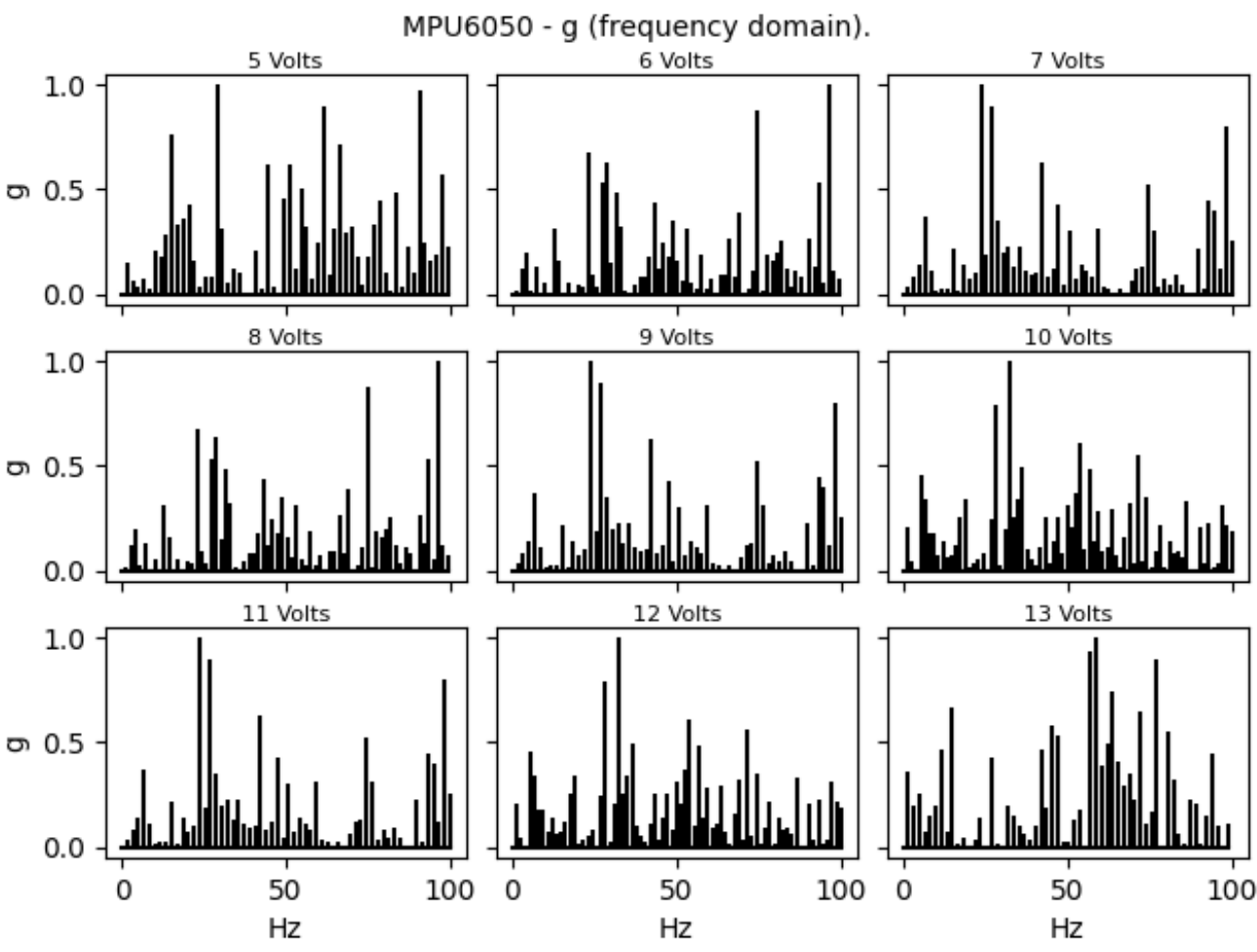

Source: Authors.

Figure 12. Spectral composition of the signal measured by the ADXL345.

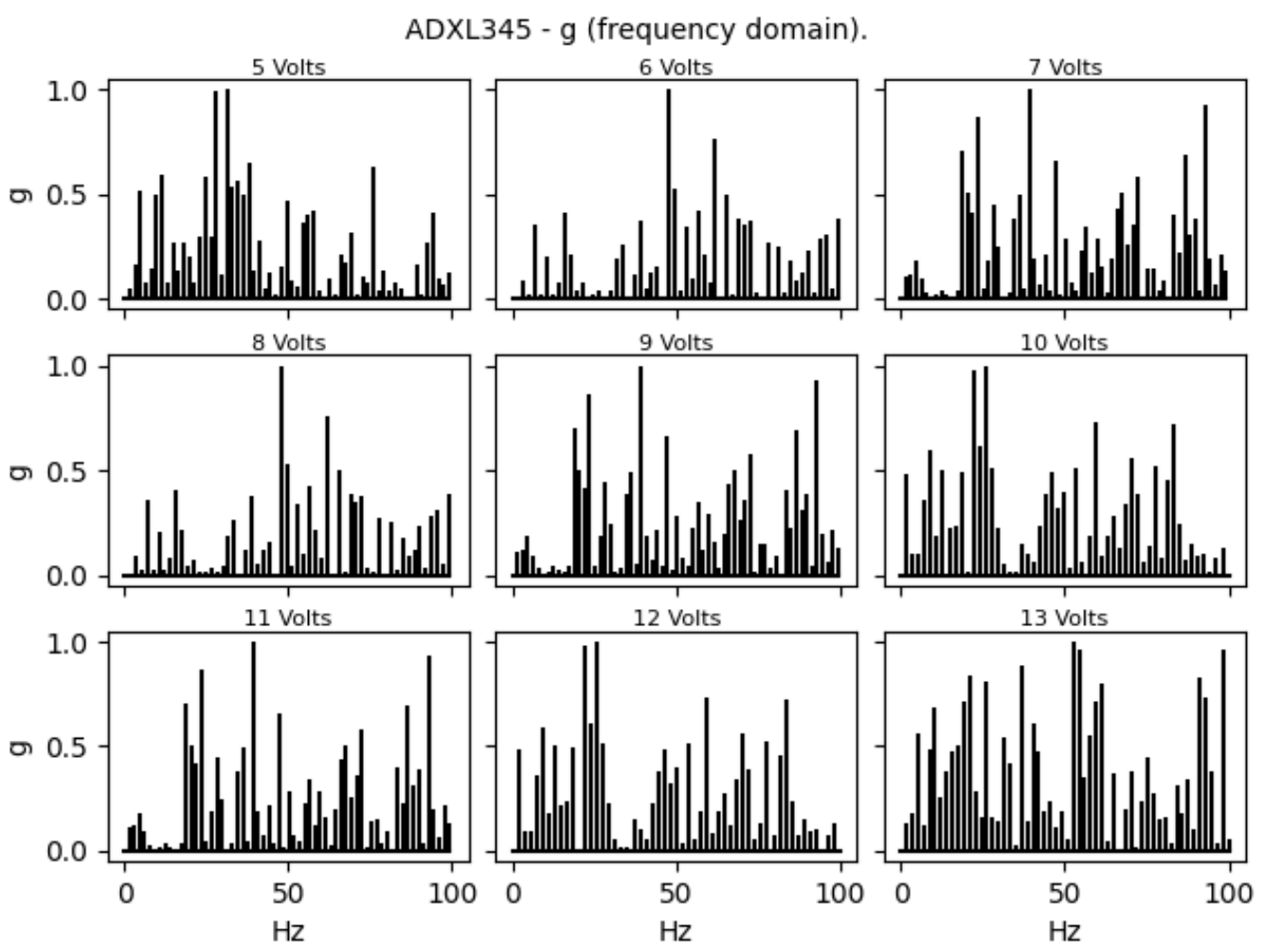

Source: Authors. 
Figure 13 shows the differences in g obtained between the spectra verified in both studied accelerometers. In each case, there seems to be some pattern in the $g_{m p u 6050}-g_{a d x l 345}$ values, however, as already said, only a deeper analysis of the data can explain it.

Figure 13. Spectral difference between the signals measured by the MPU6050 and ADXL345.
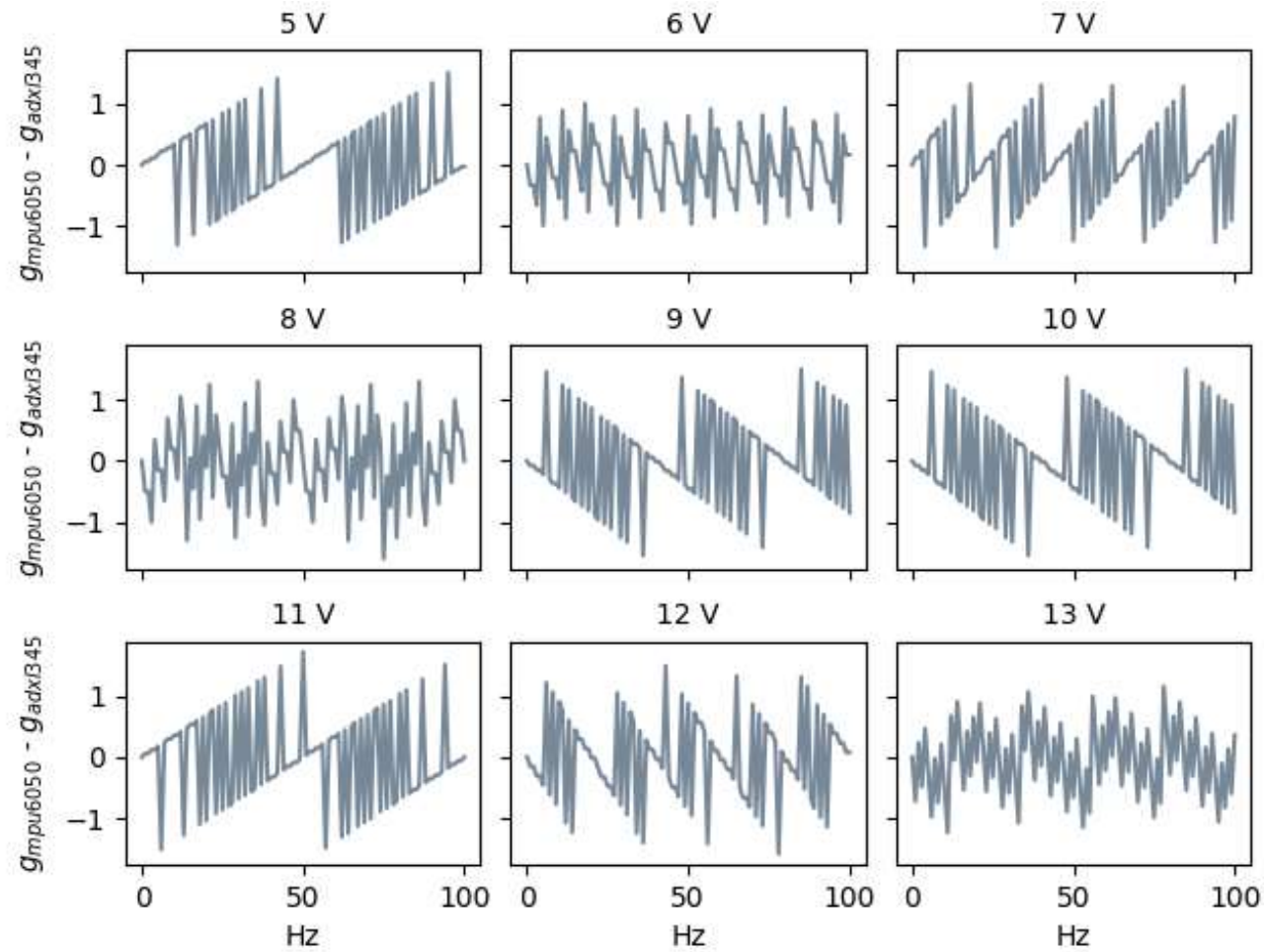

Source: Authors.

\subsection{VRE analysis}

The VRE measured for the MPU6050 presented similar behavior to that reported in the literature, however, for the ADXL345 the results obtained did not make any sense. However, the impossibility of determining the VRE was already expected due to the anomalous behavior discussed in Figure 10.

Figure 14 shows the MPU6050 VRE as function of input (g) variations and the motor operating voltage. The behavior verified is quite similar to those presented by Pham \& DeSimone (2017) and are considered satisfactory for the desired analysis.

\section{Final Considerations}

The test methodology of the employed sensors showed satisfactory results for MPU6050, however, the results measured simultaneously through the ADXL345 are not clear and allow few safe inferences. Such discrepancies may be associated with structural damage in the sensor's MEM or even in the circuit, but no conclusive statement is possible. Manufacturing nonlinearity problems and even prototyping differences for different manufacturers are reported in the literature as frequent causes of behavior like these. However, the difference between the spectra measured by one and the other, as it presents some periodic and standardized behavior, can testify against the possibility of error or damage to the circuit. 
To resolve these issues, the replication of this test methodology for accelerometers from different manufacturers and batches can provide greater statistical representation to the data and eliminate the risk of bias in the conclusions.

The collected data returned by the MPU6050 was quite clear and satisfactory for the desired analysis. As the initial objective of the research was to produce quantitative evidence that would ensure the use of sensors as monitors of mechanical vibrations, the MPU6050 was taken as suitable for this use, in this spectral range and of vibrational intensities.

Figure 14. VRE of the MPU6050 accelerometer measured as a function of operating voltage and $g$ input intensity.

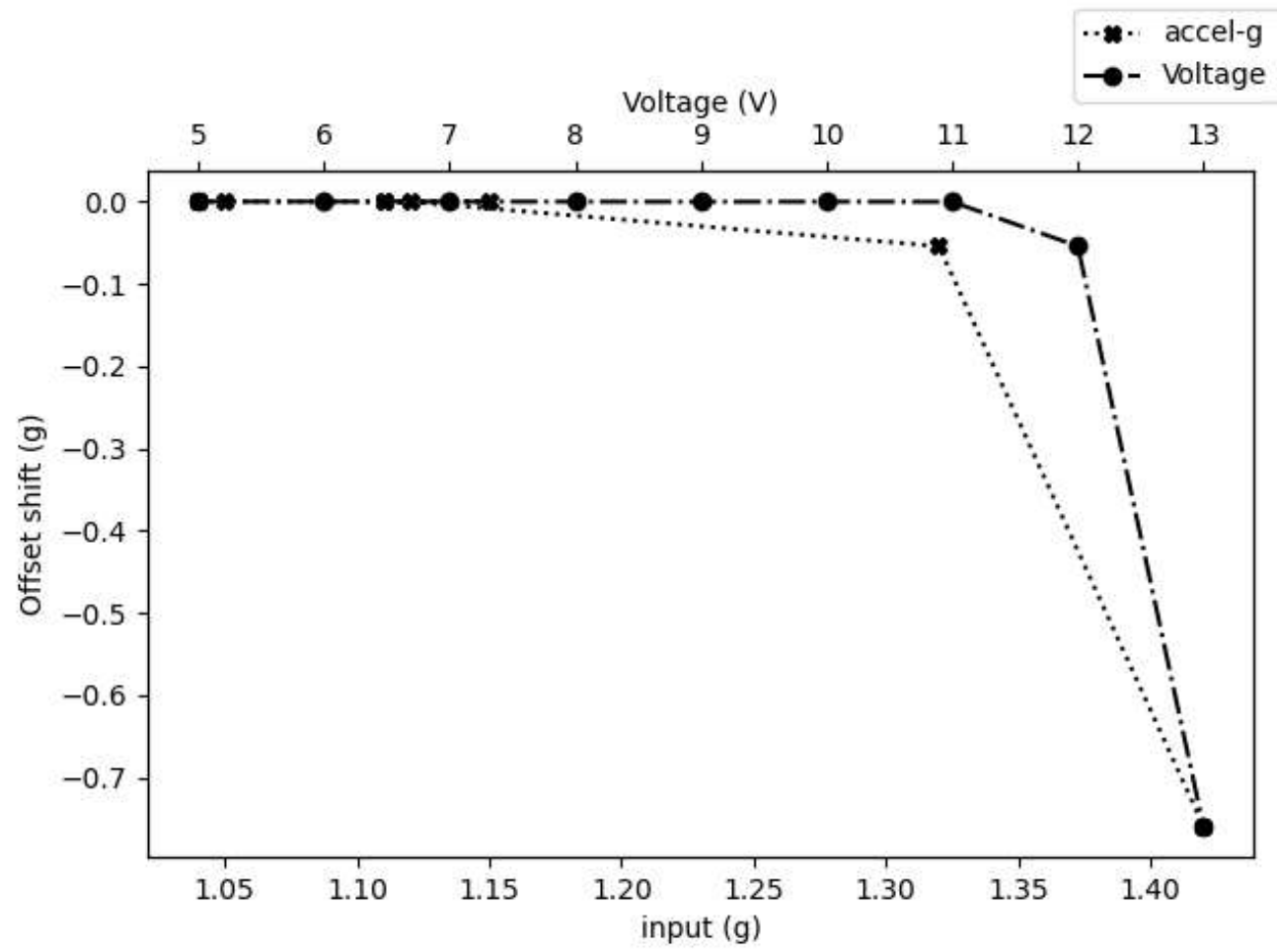

Source: Authors.

The risk of error due to production non-linearities or structural damage to the circuit or MEM requires that prior functionality tests be carried out before using the sensor, in addition to the longevity of the linearity of the response of the same sensor when exposed to vibrational signals by long periods of time, as is common when using these devices in-company. Furthermore, there may be behavioral changes in other spectral ranges $(>100 \mathrm{~Hz})$ or in vibrational intensities higher than those detected.

Even numerical analysis can be expanded, as numerical integrations for velocity and measured amplitudes as displacement were not performed in this study. Perhaps, these data can even resolve the issue of the behavior of the ADXL345 observed.

\section{Acknowledgments}

The authors thank GESESC (Study Group on Energy Systems and Computational Simulation) for providing software developed by the group and the Federal Institute of Minas Gerais Campus Arcos for providing the computational infrastructure. 


\section{References}

Albarbar, A., \& Teay, S. H. (2017). MEMS accelerometers: testing and practical approach for smart sensing and machinery diagnostics. In D. Zhang \& B. Wei (Eds.), Advanced Mechatronics and MEMS Devices II (1st ed., pp. 19-40). Springer.

Bao, M. (2005). Analysis and design principles of MEMS devices (1st ed.). Elsevier Science.

Bao, M. H. (2000). Micro mechanical transducers: pressure sensors, accelerometers and gyroscopes (1st ed.). Elsevier Science.

Blodt, M., Chabert, M., Regnier, J., \& Faucher, J. (2006). Mechanical load fault detection in induction motors by stator current time-frequency analysis. IEEE Transactions on Industry Applications, 42(6), 1454-1463.

Combescure, D., \& Lazarus, A. (2008). Refined finite element modelling for the vibration analysis of large rotating machines: Application to the gas turbine modular helium reactor power conversion unit. Journal of Sound and Vibration, 318(4-5), 1262-1280.

Correa, J. C. A. J., \& Guzman, A. A. L. (2020). Mechanical Vibrations and Condition Monitoring (1st ed.). Academic Press.

Dukkipati, R. V. (2010). Mechanical vibrations. Alpha Science International.

Farrar, C. R., Doebling, S. W., \& Nix, D. A. (2001). Vibration-based structural damage identification. Philosophical Transactions of the Royal Society of London. Series A: Mathematical, Physical and Engineering Sciences, 359(1778), 131-149.

Fisher, C. J. (2010). Using an accelerometer for inclination sensing. Analog Devices. https://www.analog.com/en/app-notes/an-1057.html

Friswell, M., Penny, J., Garvey, S., \& Lees, A. (2010). Dynamics of Rotating Machines (Cambridge Aerospace Series). Cambridge: Cambridge University Press. doi:10.1017/CBO9780511780509

Hunter, J. D. (2007). Matplotlib: A 2D graphics environment. Computing in science \& engineering, 9(03), 90-95.

Harris, C. R., Millman, K. J., van der Walt, S. J., Gommers, R., Virtanen, P., Cournapeau, D., ... Oliphant, T. E. (2020). Array programming with NumPy. Nature, 585, 357-362. https://doi.org/10.1038/s41586-020-2649-2

He, J., Zhou, W., Yu, H., He, X., \& Peng, P. (2018). Structural Designing of a MEMS Capacitive Accelerometer for Low Temperature Coefficient and High Linearity. Sensors, 18(2), 643. doi:10.3390/s18020643

Holanda, S.A., Silva, A.A., Araujo, C.J., \& Aquino, A.S. (2014). Study of the Complex Stiffness of a Vibratory Mechanical System with Shape Memory Alloy Coil Spring Actuator. Shock and Vibration, 162781. https://doi.org/10.1177/1045389X20924829

International Organization for Standardization. (2010). Mechanical vibration and shock - Vibration of fixed structures - Guidelines for the measurement of vibrations and evaluation of their effects on structures (ISO Standard No. 4866). Retrieved from https://www.iso.org/standard/38967.html

International Organization for Standardization. (2016). Mechanical vibration - Measurement and evaluation of machine vibration - Part 1: General guidelines (ISO Standard No. 20816-1). Retrieved from https://www.iso.org/standard/63180.html

Kelly, S. G. (2012). Mechanical vibrations: theory and applications (1st ed.). Cengage learning.

Lawes, R. (Ed.). (2014). MEMS Cost Analysis: From Laboratory to Industry. CRC Press.

Lees, A. W., Sinha, J. K., \& Friswell, M. I. (2009). Model-based identification of rotating machines. Mechanical Systems and Signal Processing, 23(6), 1884-1893. https://doi.org/10.1016/j.ymssp.2008.08.008

Levinzon, F. (2015). Piezoelectric accelerometers with integral electronics. Springer.

Nayfeh, A. H., \& Younis, M. (2005). Dynamics of MEMS resonators under superharmonic and subharmonic excitations. Journal of Micromechanics and Microengineering, 15(10), 1840-1847. https://doi.org/10.1088/0960-1317/15/10/008

Pham, L., \& DeSimone, A. (2017). Vibration Rectification in MEMS Accelerometers. Analog Devices. https://www.analog.com/ru/technical-articles/vibrationrectification-in-mems-accelerometers.html

Prawin, J., \& Anbarasan, R. (2021). A novel Mel-frequency cepstral analysis based damage diagnostic technique using ambient vibration data. Engineering Structures, 228, 111552. https://doi.org/10.1016/j.engstruct.2020.111552

Silva, F. A. (2014). Smart Sensors and MEMS: Intelligent Devices and Microsystems for Industrial Applications [Book News]. IEEE Industrial Electronics Magazine, 8(3), 74-74. 10.1109/MIE.2014.2335418

Virtanen, P., Gommers, R., Oliphant, T. E., Haberland, M., Reddy, T., Cournapeau, D., Burovski, E., Peterson, P., Weckesser, W., Bright, J., Van Der Walt, S. J., Brett, M., Wilson, J., Millman, K. J., Mayorov, N., Nelson, A. R. J., Jones, E., Kern, R., Larson, E., ... Tygier, S. (2020). SciPy 1.0: fundamental algorithms for scientific computing in Python. Nature Methods. https://doi.org/10.1038/s41592-019-0686-2

Tanaka, M. (2007). An industrial and applied review of new MEMS devices features. Microelectronic engineering, 84(5-8), 1341-1344.

Walter, P. L. (1997). The history of the accelerometer. Sound and vibration, 31(3), 16-23.

Wang, Y., He, Z., \& Zi, Y. (2010). Enhancement of signal denoising and multiple fault signatures detecting in rotating machinery using dual-tree complex wavelet transform. Mechanical Systems and Signal Processing, 24(1), 119-137. 10.1016/j.ymssp.2009.06.015.

Yan, Y.J., Cheng, L., Wu, Z. \& Yam, L.H. (2007). Development in Vibration-Based Structural Damage Detection Technique. Mechanical Systems and Signal Processing, 21(5), 2198-2211. 10.1016/j.ymssp.2006.10.002. 